\title{
Effect of amlodipine, a calcium channel antagonist, on gonadal steroid of male Wistar albino rats
}

This article was published in the following Dove Press journal:

Journal of Experimental Pharmacology

13 March 2010

Number of times this article has been viewed

\author{
FC Onwuka' \\ KC Patrick-I wuanyanwu' \\ CK Nnodu' \\ O Erhabor ${ }^{2}$ \\ 'Department of Biochemistry, \\ ${ }^{2}$ Department of Haematology, College \\ of Health Sciences, University of Port \\ Harcourt, Port Harcourt, Rivers State, \\ Nigeria
}

\begin{abstract}
This study was carried out to investigate the effect of prolonged intake of calciumchannel blocker amlodipine, an antihypertensive drug on gonadal steroid hormone (testosterone) of male albino rats. Three different concentrations of amlodipine (0.01, 0.02 and $0.03 \mathrm{mg} / \mathrm{kg}$ body weight) was administered orally to three different groups (B, C, and D) of experimental male Wistar albino rats $(\mathrm{n}=8)$ for six weeks. Group A rats were fed normal diet without amlodipine $(\mathrm{n}=8)$ served as the control. The administration of amlodipine significantly reduced testosterone level in the following order, group $\mathrm{A}(0.22 \pm 0.01)>\mathrm{B}(0.18 \pm 0.01)>$ $\mathrm{C}(0.14 \pm 0.01)>\mathrm{D}(0.10 \pm 0.01)$. The reduction in testosterone levels corresponded with an increase in the concentration of amlodipine administered to male Wistar albino rats. The observation in this study reveals that long-term treatment of male Wistar rats with calciumchannel blocker and antihypertensive (amlodipine) produces a significant reduction in the level of testosterone a hormone associated with decreased ability of men to enjoy sex and to develop good quality erections. There is the need for a large scale study to investigate the potential effect of long-term antihypertensive therapy with amlodipine on sexual dysfunction in men.
\end{abstract}

Keywords: calcium-channel blocker, amlodipine, antireproductive, antihypertensive drugs, gonadal steroid, and low libido

\section{Introduction}

Amlodipine (as besylate, mesylate. or maleate) is a long-acting calcium-channel blocker (dihydropyridine) class used as an antihypertensive and in the treatment of angina. Like other calcium-channel blockers, amlodipine acts by blocking transmembrane calcium influx through the calcium channel resulting in the relaxation of the smooth muscle in the arterial wall, decreasing peripheral resistance and hence reducing blood pressure. ${ }^{1}$ In angina it increases blood flow to the heart muscle. ${ }^{2}$ Calcium is vital in many biological processes including hormonal secretion, mitosis, reproduction, fertility, and regulation of gene expression. However the effects of calcium-channel blockers to a large extent remain confined to the heart and vascular smooth muscles. ${ }^{3}$ Despite exhibiting substantial cardiovascular selectivity, reports exist which suggest that calcium-channel blockers may have anti-reproductive effects in males on long-term treatment. ${ }^{4-7}$

Problems with sexual function have been a long-standing concern in the treatment of hypertension and may influence the choice of treatment regimens and decisions to discontinue drugs. The Treatment of Mild Hypertension Study ${ }^{8}$ (TOMHS) provides an excellent opportunity for examination of sexual function and the effects of treatment
Correspondence: Erhabor Osaro Blood Sciences Department, Royal Bolton Hospital, Bolton Lancashire, UK Tel +447932363217

Email n_osaro@yahoo.com 
on sexual function in men and women with stage I diastolic hypertension. TOMHS was a double-blind, randomized controlled trial of 902 hypertensive individuals treated with placebo or one of five active drugs (acebutolol, amlodipine maleate, chlorthalidone, doxazosin maleate, or enalapril maleate). The results from this study showed that long-term incidence of erection problems in treated hypertensive men although low is higher with chlorthalidone treatment. The rate of reported sexual problems in hypertensive women is low and does not appear to differ by type of drug. Sexual dysfunction associated with antihypertensive therapies can negatively impact the ability of patients to stay on therapy on a long-term basis and can lead to deterioration in patient quality of life..$^{9,10}$

Testosterone is a steroid hormone from the androgen group. In mammals, testosterone is primarily secreted in the testes of males and the ovaries of females, although small amounts are also secreted by the adrenal glands. It is the principal male sex hormone and an anabolic steroid. Testosterone plays a key role in health and well-being as well as preventing osteoporosis. On average, an adult human male body produces about forty to sixty times more testosterone than an adult human female body, but females are, from a behavioral perspective (rather than from an anatomical or biological perspective), more sensitive to the hormone. ${ }^{11}$ Andropause, a condition in which the testosterone level slowly declines with age, also decreases a man's ability to enjoy sex and to develop good quality erections. ${ }^{12,13}$ In addition to experiencing a decrease in sexual desire and erectile dysfunction, men with a lowered testosterone level may also notice changes in mood and emotions. However, the overall ranges for male and female are very wide, such that the ranges actually overlap at the low and high ends, respectively.

The purpose of the present study was to investigate whether treatment of male rats with the calcium antagonist amlodipine, used in the treatment of hypertension and angina, interferes with the gonadal steroid-testosterone levels of male Wistar albino rats.

\section{Materials and methods}

Thirty-two adult male Wistar albino rats (170-200 g) used in this study were obtained from the Animal House, Department of Biochemistry, University of Port Harcourt, and Port Harcourt, Nigeria. They were housed in standard cages (Griffin and George Modular Cage System) and left to acclimatize for seven days to laboratory conditions before the commencement of the experiment. During the acclimatization, the animals were fed with pelleted rat chow and water ad libitum. The rats were weighed and randomly assigned into four study groups of eight rats per group. They were kept under adequate ventilation at room temperature and relative humidity of $28 \pm 2{ }^{\circ} \mathrm{C}$ and $46 \%$, respectively.

The 32 rats were arranged into four groups of eight animals each: group A was given normal feed only; group $\mathrm{B}$ received feed and $0.01 \mathrm{mg}$ amlodipine/ $\mathrm{kg}$ body weight; group $\mathrm{C}$ received feed and $0.02 \mathrm{mg}$ amlodipine $/ \mathrm{kg}$ body weight; and group D received feed and $0.03 \mathrm{mg}$ amlodipine/ $\mathrm{kg}$ body weight.

\section{Experimental design}

Animals in group A were fed normal diet and served as control group. Groups B, C, and D consisted of rats placed on normal diet and administered different concentrations (0.01, 0.02 and $0.03 \mathrm{mg}$ ) of amlodipine $/ \mathrm{kg}$ body weight. The amlodipine was administered in the food pellets. Six weeks after the feeding trials, the animals were sacrificed by suffocation using chloroform and dissected. Blood was collected by cardiac puncture using sterile syringe/needle and transferred to lithium heparin anticoagulant bottles. Clear serum samples were obtained by centrifuging the whole blood samples.

\section{Statistical analysis}

Statistical analysis was analyzed using Statistical Package for Social Sciences (version 10; SPSS Inc., Chicago, IL), which was used to generate frequency distribution and percentage prevalence of the various parameters. Descriptive analyses of percentages of categorical variables were reported. Comparisons were assessed using mean and chi-square test. A $P$-value of $<0.05$ was considered statistically significant in all statistical comparison.

\section{Biochemical assay}

Estimation of testosterone level of the experimental rats was carried out using the method employed in microplate automated reader using Clinotech enzyme-linked immunosorbent assay (ELISA) hormonal assay kits (Clinotech Diagnostic, Richmond, Canada). The Clinotech enzyme immunoassay test is intended for the quantitative determination of testosterone in serum. The testosterone enzyme immunoassay (EIA) is based on the principle of competitive binding between testosterone in the test specimen and testosterone conjugate for a constant amount of rabbit anti-testosterone. The test is highly sensitive. The minimum concentration of the testosterone ELISA assay 
as measured by 2 standard deviations from the mean of a zero standard is estimated to be $0.05 \mathrm{ng} / \mathrm{mL}$.

\section{Results}

The effect of prolonged administration of amlodipine on serum levels of gonadal steroid (testosterone) of male albino rats is as shown in Table 1. Result indicates that treatment of male rats with different concentrations $(0.01,0.02$, and $0.03 \mathrm{mg} / \mathrm{kg}$ body weight) of amlodipine significantly $(P \leq 0.01)$ reduced gonadal steroid when compared to control rats. The reduction in gonadal steroid (testosterone) corresponded with increase in the concentration of amlodipine. This was evidenced by a marked reduction in the levels of testosterone of male rats treated with $0.03 \mathrm{mg} / \mathrm{kg}$ body weight when compared to rats treated with lower concentration and the rats in the control group.

\section{Discussion}

The principal finding of this study is that amlodipine reduces gonadal steroid in male albino rats. It was generally observed that an increase in the concentration of amlodipine caused a decrease in serum levels of gonadal steroids. A decrease in the level of testosterone caused by corresponding rise in the concentration of amlodipine administered to rats was an indication that prolonged administration of the calcium-channel blocker, amlodipine had a negative effect on sexual reproduction in male rats. The result of this study is in agreement with a previous report by Almeida and colleagues, ${ }^{14}$ which observed that treatment with a dose of $0.04 \mathrm{mg}$ amlodipine besylate/ rat/day for 30 days decreased plasma follicle-stimulating hormone and testosterone but not luteinizing hormone or prolactin concentrations. The decrease in testosterone levels in the serum of albino rats was attributed to prolonged intake of the antihypertensive drug which affected the gonad causing low libido and low sperm count. The result of this study is however in contrast with the findings of Reaven and colleagues ${ }^{15}$ and Nafziger and colleagues ${ }^{16}$ who argued that

Table I Effect of prolonged intake of amlodipine on gonadal steroid of male albino rats

\begin{tabular}{llll}
\hline Groups & Treatment & $\begin{array}{l}\text { Testosterone } \chi^{2} \\
(\mathbf{n g} / \mathbf{m L})\end{array}$ & P-value \\
\hline A & Normal feed & $0.22 \pm 0.0 \mathrm{I}^{\mathrm{a} 88.24}$ & $P=0.0 \mathrm{I}$ \\
B & $0.01 \mathrm{mg} / \mathrm{kg} \mathrm{BW} \mathrm{Amlodipine}$ & $0.18 \pm 0.0 \mathrm{I}^{\mathrm{b}}$ & \\
C & $0.02 \mathrm{mg} / \mathrm{kg}$ BW Amlodipine & $0.14 \pm 0.0 \mathrm{I}^{\mathrm{c}}$ & \\
D & $0.03 \mathrm{mg} / \mathrm{kg} \mathrm{BW} \mathrm{Amlodipine}$ & $0.10 \pm 0.0 \mathrm{I}^{\mathrm{d}}$ & \\
\hline
\end{tabular}

Notes: Values are means \pm SEM. $n=8$ rats in each group. Means with different superscript letters $(a, b, c, d)$. Amlodipine induced a dose-dependent decline in testosterone level $(P=0.0 \mathrm{I})$.

Abbreviations: BW; SEM, standard error of mean. amlodipine, in addition to reducing blood pressure, improves glucose tolerance, diminishes hyperinsulinemia, increases serum adrenal androgens (DHEA-S and androstenedione), and decreases serum adrenal glucocorticoid (cortisol) levels. The physiological effects of decreased serum levels of DHEA and DHEA-S are not well understood. It has been suggested that in the context of severe chronic illness, there is a shift in adrenal steroid synthesis which may be necessary for survival. ${ }^{17}$ However DHEAS was found significantly associated with coital frequency and desire for sex and sexual functions in men in a previous study. ${ }^{18}$

The effects of the antihypertensive drug, amlodipine, a calcium-channel blocker, in this study is consistent with previous report which observed cases of infertility and reduced libido in men with history of long-term use of calcium-channel blockers. ${ }^{4-6}$ The exact mechanism of calcium-channel blockers in causing infertility remains to be completely elucidated. However a previous report by Rabia and colleagues ${ }^{7}$ suggests that long-term treatment with amlodipine might be associated with significant testicular regression and reduction in serum testosterone. Similarly Garko and colleagues ${ }^{8}$ reported that sexual dysfunction is associated with hypertension or antihypertensive therapies and that it may negatively impact the ability of patients to stay on therapy and lead to deterioration in patient's quality of life. In a previous report, Ferrario and colleagues suggested that it may be important for practitioners to become familiar with the wide variation in sexual side effects produced by antihypertensive agents and to discuss the potential occurrence of these side effects with their patients. ${ }^{9}$ Problems with sexual function have been a longstanding concern in the treatment of hypertension and may influence the choice of treatment regimens and decisions to discontinue drugs. The Treatment of Mild Hypertension Study (TOMHS) provides an excellent opportunity for examination of sexual function and the effect of treatment on sexual function in men and women with stage I diastolic hypertension. TOMHS was a double-blind, randomized controlled trial of 902 hypertensive individuals treated with placebo or one of five active drugs (acebutolol, amlodipine maleate, chlorthalidone, doxazosin maleate, or enalapril maleate). The study concluded that long-term incidence of erection problems in treated hypertensive men is low but is higher with chlorthalidone treatment. ${ }^{10}$

This present study has shown that long-term treatment of male Wistar rats with calcium-channel blockers and antihypertensive (amlodipine) produces a significant reduction in the level of testosterone a hormone associated 
with decreased man's ability to enjoy sex and to develop good quality erections. There is the need for a large scale study to investigate the potential effect of long-term antihypertensive therapy with amlodipine on sexual dysfunction in men.

\section{Disclosures}

The authors report no conflicts of interest in this work.

\section{References}

1. Frick MH, McGibney D, Tyler HM, et al. Amlodipine: a double blind evaluation of the dose-response relationship in mild to moderate hypertension. J Cardiovasc Pharmacol. 1988;12(7):76-79.

2. Choi SM, Seo MJ, Kang KK, Kim JH, Ahn BO, Yoo M. Beneficial effects of the combination of amlodipine and losartan for lowering blood pressure in spontaneously hypertensive rats. Arch Pharm Res. 2009;32(3):353-358.

3. Glasser SP, West TW. Clinical safety and efficacy of once-a-day amlodipine for chronic stable angina pectoris. Am J Cardiol. 1988;62:518-522.

4. Yoshida J. Amlodipine besylate. Eur J Pharmacol. 2003;472:23-31.

5. Benoff S. Voltage-dependent calcium channels in mammalian spermatozoa. Front Biosci. 1998;3:1220-1240.

6. Nowak R. Antihypertension drugs may double as male contraceptive. J NIH Res. 1994;6:27-28.

7. Rabia L, Ghulam ML, Muhammad A. Effects of amlodipine on serum testosterone, testicular weight and gonado-somatic index in adult rats. J Ayub Med Col Abbottabad. 2008;20(4):8-10.
8. Garko B, Ogunsina MO, Danbauchi SS. Sexual dysfunction in hypertensive patients: implications for therapy. Ann Afr Med. 2005;4(2):46-45.

9. Ferrario CM, Levy P. Sexual dysfunction in patients with hypertension: implications for therapy. J Clin Hypertens. 2008;4(6):424-432.

10. Grimm RH Jr, Grandits GA, Prineas RJ, et al. Long-term effects on sexual function of five antihypertensive drugs and nutritional hygienic treatment in hypertensive men and women. Treatment of Mild Hypertension Study (TOMHS). Hypertension. 1997;29(1):8-14.

11. Dabbs M, Dabbs JM. Heroes, Rogues, and Lovers: Testosterone and behavior. New York, NY: McGraw-Hill; 2000.

12. Heaton JP. Hormone treatments and preventive strategies in the aging male: whom and when to treat? Rev Urol. 2003;5(Suppl 1):S16-S21.

13. McCulloch A. Case scenarios in androgen deficiency. Rev Urol. 2003;5(Suppl 1):S41-S48.

14. Almeida SA, Teofilo JM, Anselmo Franci JA, Brentegani LG, Lamano-Carvallo TL. Antireproductive effect of the calcium channel blocker amlodipine in male rats. Exp Toxicol Pathol. 2000; 52:353-356.

15. Reaven GM. Banting lecture 1988. Role of insulin resistance in human disease. Diabetes. 1988;37:1595-1607.

16. Nafziger AN, Herrington DM, Bush TL. Dehydroepiandrosterone and dehydroepiandrosterone sulfate: their relation to cardiovascular disease. Epidemiol Rev. 1991;13:267-293.

17. Suzuki H, Tominaga T, Kamagai $\mathrm{H}$, et al. Effects of first-line antihypertensive agents on sexual functions and sex hormones. $J$ Hypertens. 1988;6:649-651.

18. Goh VH, Tong TY. Sleep, sex and steroid hormones, sexual activities and aging in Asian men. J Androl. 2009; Aug 14 [Epub ahead of print].
Journal of Experimental Pharmacology

\section{Publish your work in this journal}

The Journal of Experimental Pharmacology is an international, peerreviewed, open access journal publishing original research, reports, reviews and commentaries on all areas of laboratory and experimental pharmacology. The manuscript management system is completely online and includes a very quick and fair peer-review system.

\section{Dovepress}

Visit http://www.dovepress.com/testimonials.php to read real quotes from published authors. 